\title{
Análise estatística das características de vazão do córrego Capetinga
}

Cícero L. da Silva ${ }^{1}$

\begin{abstract}
1 Faculdade de Agronomia e Medicina Veterinária da Universidade de Brasília. Campus Universitário Darcy Ribeiro, Asa Norte, CEP 70910-900, Brasília, DF. Fone: (61) 307-2821 e 307-2825. E-mail: cicero@unb.br (Foto)
\end{abstract}

Protocolo 169 - 13/11/2002 - Aprovado em 26/8/2003

\begin{abstract}
Resumo: Em 1996 foram instalados, num dos córregos da Fazenda Experimental da Universidade de Brasília, um linígrafo e três pluviógrafos, iniciando-se, assim, a medição de algumas variáveis hidrometeorológicos referentes à bacia do córrego Capetinga. Conhecendo-se as médias mensais da vazão e as médias específicas, traçaram-se as respectivas curvas de permanência das vazões médias mensais desse córrego. Dessas curvas, extraíram-se os valores da vazão associada à permanência de $95 \%\left(\mathrm{Q}_{95}\right)$ e da vazão específica associada à permanência de $95 \%\left(\mathrm{q}_{95}\right)$. Não houve discrepância entre os valores de $q_{95}$ e a razão entre $Q_{95}$ e a área da bacia. Através da distribuição de valores extremos do tipo 1 ou de Gumbel, determinaram-se os períodos de retorno das vazões máximas instantâneas anuais e das mínimas anuais, com duração de sete dias. Calcularam-se, também, os eventos esperados dos máximos anuais e dos mínimos com a mencionada duração, para os períodos de retorno de 5, 10, 20, 50 e 100 anos. Verificou-se que a distribuição de Gumbel, no caso dos máximos, adaptou-se muito bem tanto na descrição dos eventos simulados quanto na descrição dos eventos observados, ao passo que no caso dos mínimos não houve discrepância, seja nos eventos simulados ou nos observados.
\end{abstract}

Palavras-chave: gestão de recursos hídricos, máximos e mínimos anuais, vazão

\section{Statistical analysis of the discharge characteristics of the Capetinga streamlet}

\begin{abstract}
In 1996 one water level recorder and three recording rain gauges were installed in the Capetinga streamlet watershed at 'Fazenda Água Limpa' at University of Brasília, allowing to measure some hydro-meteorological parameters. Knowing the monthly average of the stream flow and the specific average, it was possible to draw the respective permanence curves of the monthly average discharge of Capetinga streamleat. From these curves it was possible to determine values of minimum monthly average at $95 \%$ probability level $\left(Q_{95}\right)$ and of minimum specific monthly average at $95 \%$ probability level $\left(q_{95}\right)$. There was not discrepancy among the $q_{95}$ and the ratio betwen $\mathrm{Q}_{95}$ and the watershed area. The general extreme value type 1 or Gumbel distribution was used to calculate the return period of the maximum instantaneus annual stream as well the least annual stream with seven days period. The return periods of $5,10,20,50$ and 100 years it was evaluated for maximum and minimum events. It was found that Gumbel distribution adjusted very well to describe the maximum events observed as well as calculated ones, whereas for the minimum events there was no discrepancy.
\end{abstract}

Key words: management of water resources, annual maximum and minimum, discharge

\section{INTRODUÇÂO}

A intensificação das atividades agrícolas na região dos cerrados, com o uso de tecnologias mais avançadas, tais como: plantio direto e irrigação, tem levado os produtores da região a obterem produtividades e lucratividades sempre mais elevadas, porém o uso indiscriminado da água para fins de irrigação pode levar a uma situação de conflitos entre as demandas para consumo humano e a agricultura. A área irrigada no Distrito Federal, segundo Christofides (2001), é de aproximadamente
12.000 ha com a qual se poderia, numa primeira análise, concluir que é um número pequeno comparado com a área irrigada do Brasil que hoje ultrapassa os três milhões de hectares; no entanto, se se considerar uma demanda média de $1 \mathrm{~L} \mathrm{~s}^{-1} \mathrm{ha}^{-1}$, essa área consumiria $12 \mathrm{~m}^{3} \mathrm{~s}^{-1}$ de água, suficiente para atender a uma população de mais de cinco milhões de habitantes, considerando-se um consumo médio de $200 \mathrm{~L} \mathrm{pessoa}^{-1} \mathrm{~d}^{-1}$.

A relativa carência de água na região do Distrito Federal se deve ao fato de se tratar de uma região alta, tipicamente de nascentes. No Distrito Federal chove em média $1420 \mathrm{~mm} \mathrm{ano}^{-1}$, 
apresentando uma disponibilidade hídrica média de $2,8 \mathrm{~km}^{3}$ $\mathrm{ano}^{-1}$, o que corresponde a $1.400 \mathrm{~m}^{3}$ habitante $\mathrm{ano}^{-1}$, valor per capita que, de acordo com a FAO, citado por Lima (2000) indica uma situação de risco eminente.

A implantação de grandes equipamentos de irrigação na região do Planalto Central, em que o Distrito Federal também não foge à regra, não é precedida por um estudo adequado das potencialidades hídricas da bacia. Normalmente, o que se faz é uma única medida da vazão no córrego no período mais seco do ano, procedimento insuficiente pois, historicamente, dentro dos períodos secos, pode haver anos mais secos que o ano em que se fez a medida de vazão; além disso, está sendo recomendada, na região, a construção de pequenas barragens para promover a regularização do córrego, armazenando água dos períodos de excesso para ser gasta nos períodos de maior demanda e menor disponibilidade. Esta estratégia poderia dar certo, se não fossem as suas pequenas dimensões.

Outra dificuldade a ser encarada na gestão dos recursos hídricos na área é a pouca disponibilidade de registros históricos de vazão nos pequenos cursos d'água, cuja deficiência se deve ao fato desses registros necessitarem de uma tecnologia cara e exigente em mão-de-obra especializada, de uso mais comum, nos cursos d'água de maior volume, que interessam ao setor elétrico. A deficiência de dados históricos dos pequenos cursos d'água dificulta, inclusive, o uso da técnica de regionalização de vazões, que consiste na transferência de parâmetros hidrológicos de uma bacia para outras de características hidrológicas e climáticas semelhantes. Silveira et al. (1994), com o intuito de reduzir os custos de obtenção de dados em algumas pequenas bacias localizadas no Rio Grande do Sul, estabeleceram uma técnica para registro de vazões, utilizando calhas Parshall de fundo plano, nas quais eram feitas duas observações do nível da água por dia. Este procedimento permite se obter uma estimativa das médias diárias das vazões. No caso das máximas instantâneas, tal procedimento é falho em virtude da curta duração dos picos das cheias nos pequenos cursos d’água.

Hoje em dia, as técnicas de regionalização de vazão estão muito desenvolvidas, com literatura abundante nas quais são mostradas as potencialidades e as restrições no uso da referida técnica. Bur (1997) afirma que, além da necessidade de verificação da semelhança hidrológica entre bacias, é necessário que haja, também, uma afinidade sazonal entre os diversos eventos que ocorrem nas bacias estudadas. $\mathrm{O}$ enfoque sazonal mencionado pelo autor refere-se à época de ocorrência dos eventos, isto é, se na região em estudo os eventos acontecem na mesma época nas bacias estudadas. Esta observação é importante, sobretudo no caso das máximas vazões instantâneas, já que os mínimos logicamente vão ocorrer no período mais seco do ano e, portanto, mais fáceis de atender à referida exigência.

Pires (1996) apresentou uma revisão metodológica detalhada sobre a análise de freqüência de eventos, destacando os cuidados a serem observados, tais como escolha da série (parcial ou anual), representatividade da amostra, estacionaridade, independência estocástica e tipo de distribuição estatística mais apropriada para cada caso.
Entende-se como independência estocástica a não dependência entre os eventos, isto é, o evento atual não foi influenciado pelo anterior. $\mathrm{Na}$ análise de máximos em pequenos cursos de água é bastante provável que a independência estocástica ocorra na maioria das vezes, pois em geral as cheias são muito rápidas, enquanto os mínimos são sempre independentes, visto que dependem diretamente do nível de água armazenada no lençol freático e não da vazão disponível do dia anterior.

Eventos extremos não seguem uma distribuição normal, são mais adaptados à distribuição generalizada de valores extremos (GEV), definidas por Chow et al. (1988) como dos tipos I, II e III, ou de Gumbel, Frechet e Weibull, respectivamente. Diversos autores usaram essas distribuições para previsão de valores extremos, por exemplo, Tawn (1988) para prever o nível do mar nas localidades inglesas de Lowestof e Yarmout, Waylen \& Caviedes (1990) na análise de chuvas e vazões extremas influenciadas pelo fenômeno El Niño, no Chile.

Haktanir (1992) comparou os resultados obtidos por 12 distribuições estatísticas, aplicadas na previsão de cheias máximas em 44 bacias ou sub-bacias na região de Anatólia, na Turquia, e concluiu que os melhores resultados para previsão desses eventos ocorreram através da distribuição Log-Normal de 2 e 3 parâmetros e da distribuição de Gumbel.

Acredita-se que, para qualquer uso da água, a importação de dados hidrológicos de uma bacia para outra de características hidrológicas e climáticas semelhantes, é melhor que uma simples medida de vazão no período mais seco do ano, ainda mais se nessa importação for possível de disponibilizar os volumes mensais produzidos e os máximos anuais instantâneos. Pela importância de se disponibilizar dados hidrológicos de pequenas bacias hidrográficas, destacam-se os seguintes objetivos para este artigo:

1. Análise das vazões médias mensais mínimas e máximas e estabelecimento de uma relação entre o total anual de precipitação e a vazão média anual;

2. Determinação, a partir das curvas de permanência da $\mathrm{Q}_{95}$ (vazão associada à permanência de $95 \%$ ) e da $\mathrm{q}_{95}$ (vazão específica associada à permanência de 95\%) para o córrego Capetinga;

3. Determinação, para o mesmo córrego das vazões mínimas e das vazões específicas mínimas, ambas com duração de sete dias, para períodos de retorno de: 5, 10, 20, 50 e 100 anos;

4. Determinação, para o mesmo córrego, das vazões máximas instantâneas e das vazões máximas específicas instantâneas, para períodos de retorno de 5, 10, 20, 50 e 100 anos.

\section{MATERIAL E MÉTODOS}

\section{Descrição da bacia}

A bacia do córrego Capetinga, a qual pode ser visualizada na Figura 1, está localizada no Sudeste do Distrito Federal, na região Centro-Oeste do Brasil, cujo centro aproximado corresponde a uma latitude de $15^{\circ} 52^{\prime} \mathrm{S}$ e $47^{\circ} 52^{\prime} \mathrm{W}$ de longitude. A área da bacia é de $9,624 \mathrm{~km}^{2}$ e a altitude varia de 1057 a 1200 m. A Figura 1 apresenta uma visualização da bacia, cuja 
declividade média é de aproximadamente $3,3 \%$, enquanto a declividade do principal curso d'água é de $1,8 \%$. O coeficiente de compacidade da bacia é de 1,09, indicando que a bacia em estudo é bastante arredondada e, conseqüentemente, propicia cheias elevadas e de curta duração e a densidade de drenagem é de $0,49 \mathrm{~km}^{-1}$. A vegetação predominante na bacia é do tipo cerrado, constituída por árvores, arbustos e gramíneas (em torno de $70 \%$ da área); o restante é formado por campo limpo, e próximo aos cursos de água encontra-se uma cobertura vegetal típica de mata ciliar. Em sua maioria, os solos são do tipo Cambissol, porém nos locais onde o cerrado é encontrado com mais vigor, ele é do tipo Latossol Vermelho-amarelo e profundo e nos locais de mata ciliar encontram-se os solos orgânicos. As principais características climáticas da bacia são encontradas na Tabela 1, sendo a precipitação média anual para os anos hidrológicos estudados, de $1371 \mathrm{~mm}$, concentrada nos meses de outubro a abril.

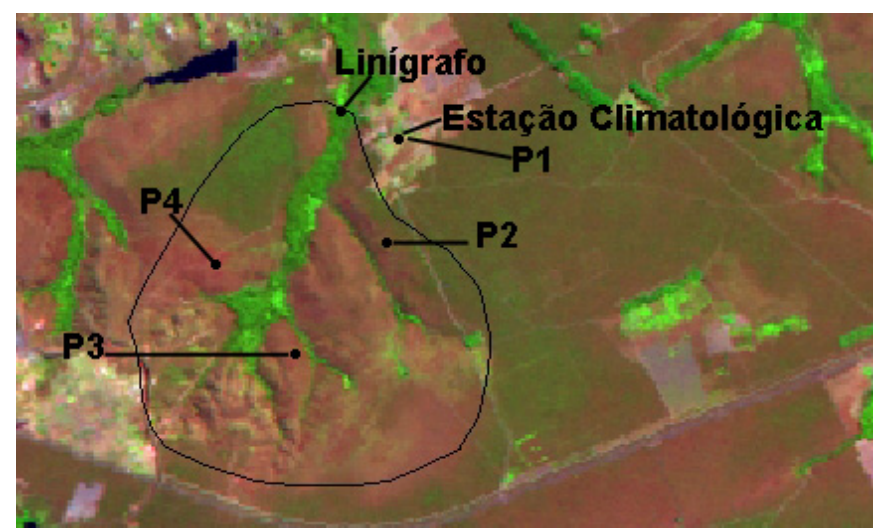

Figura 1. Visualização da bacia do córrego Capetinga, mostrando os pontos de medida das precipitações, a estação climatológica e o linígrafo

\section{Obtenção dos parâmetros meteorológicos e da vazão}

Para se medir a precipitação foram instalados, na bacia, três pluviógrafos devidamente distribuídos. Próximo à fronteira dessa bacia existe uma estação meteorológica, possibilitando a obtenção dos dados de temperatura e umidade relativa do ar e mais um ponto de medida da precipitação que, juntamente com os outros três recém-mencionados, possibilitou o cálculo da precipitação média pelo método de Thiesen, conforme sugerido por Chow et al. (1988) e apresentado na Tabela 1. Para obtenção da vazão instalou-se, na saída da bacia, um controle artificial do nível de água, assemelhando-se a um vertedor de barragem, cuja finalidade foi propiciar uma referência fixa para medição de $\mathrm{H}$; e um linígrafo cuja calibração resultou na equação $\left(\mathrm{R}^{2}=0,97\right)$ :

$$
\mathrm{Q}=6,03 \mathrm{H}^{1,64}
$$

em que:

Q - vazão, em m $\mathrm{s}^{3} \mathrm{~s}^{-1}$

H - altura de água, em m, tomada com relação à crista do controle

Ao finalizar a implantação da aparelhagem necessária, possibilitou-se o início da medição dos dados de chuva e vazão completando, em 30 de junho de 2002, seis anos hidrológicos de registros de vazão e precipitação. As Tabelas 2 e 3 mostram os valores das vazões médias mensais do córrego Capetinga (total e específica).

\section{Distribuição de valores extremos}

Mínimos e máximos hidrológicos não se adaptam à distribuição normal e são mais bem representados por uma distribuição de valores extremos, cuja função densidade de probabilidade é dada por:

$$
F(x)=\exp \left[-\left(1-k \frac{x-\mu}{\alpha}\right)^{1 / k}\right]
$$

em que:

$\mathrm{x}$ - evento analisado

$\mu \quad$ - é a moda da distribuição

$\alpha$ e k - são parâmetros da distribuição, sendo o primeiro dado pela equação seguinte e o segundo aparecendo em três condições a serem apresentadas:

Tabela 1. Precipitação média mensal (P), umidade relativa do ar (UR), temperatura média mensal (T), para os anos hidrológicos de

\begin{tabular}{|c|c|c|c|c|c|c|c|c|c|c|c|c|c|c|c|c|c|c|}
\hline \multirow{2}{*}{$\begin{array}{c}\begin{array}{c}\text { Ano } \\
\text { Hidrológico }\end{array} \\
\text { Meses }\end{array}$} & \multicolumn{3}{|c|}{$1996 / 97$} & \multicolumn{3}{|c|}{$1997 / 98$} & \multicolumn{3}{|c|}{$1998 / 99$} & \multicolumn{3}{|c|}{$1999 / 00$} & \multicolumn{3}{|c|}{$2000 / 01$} & \multicolumn{3}{|c|}{$2001 / 02$} \\
\hline & $\mathrm{P}(\mathrm{mm})$ & UR\% & $\mathrm{T}^{\circ} \mathrm{C}$ & $\mathrm{P}(\mathrm{mm})$ & UR $\%$ & $\mathrm{~T}^{\circ} \mathrm{C}$ & $\mathrm{P}(\mathrm{mm})$ & UR\% & $\mathrm{T}^{\circ} \mathrm{C}$ & $\mathrm{P}(\mathrm{mm})$ & UR\% & $\mathrm{T}^{\circ} \mathrm{C}$ & $\mathrm{P}(\mathrm{mm})$ & UR\% & $\mathrm{T}^{\circ} \mathrm{C}$ & $\mathrm{P}(\mathrm{mm})$ & UR\% & $\mathrm{T}^{\circ} \mathrm{C}$ \\
\hline Julho & 0 & 41 & 17,8 & 0 & 51 & 18,2 & 0 & 27 & 20,7 & 0 & 4 & 19,3 & 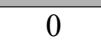 & 44 & 18,4 & 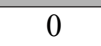 & 45 & 19,2 \\
\hline Agosto & 19,5 & 46 & 19,8 & 0 & 39 & 19,5 & 3,1 & 41 & 23,3 & 0,0 & 38 & 19,2 & 42,3 & 38 & 20,2 & 30,2 & 54 & 20,1 \\
\hline Setembro & 50,5 & 46 & 22,2 & 72,8 & 50 & 23,7 & 4,2 & 38 & 24,8 & 137,8 & 44 & 22,3 & 114,0 & 52 & 21,4 & 39,6 & 49 & 21,9 \\
\hline Outu & & 60 & 22,9 & & 59 & 23,9 & & 6 & 24,1 & & 5 & 22,7 & & 43 & 22,5 & & 65 & 21,5 \\
\hline Novembro & 240,0 & 68 & 22,2 & 171,6 & 60 & 24,0 & 269,9 & 69 & 21,5 & 15,3 & 69 & 22,4 & 281,7 & 74 & 21,4 & 3,5 & 71 & 22,5 \\
\hline Dezembro & 222,5 & 68 & 23,0 & 128,0 & 71 & 23,2 & 175,1 & 74 & 22,7 & 228,4 & 69 & 21,6 & 297,3 & 71 & 22,6 & 127,9 & 68 & 21,6 \\
\hline Janeio & & 71 & 22,3 & 301,7 & 68 & 24,4 & 60,4 & 67 & 23,0 & 246,4 & 71 & 23,6 & 123,4 & 62 & 22,3 & 184,0 & 70 & 22,9 \\
\hline Feverei & 5,9 & 63 & 22,6 & 367,6 & 67 & 24,4 & 130,6 & 66 & 22,6 & 150,8 & 6 & 22,9 & & 59 & 23,0 & & 72 & 22,0 \\
\hline Março & 266,4 & 72 & 21,7 & 261,8 & 55 & 24,5 & 196,1 & 61 & 22,6 & 212,7 & 71 & 22,7 & 245,9 & 68 & 22,1 & 251,4 & 67 & 22,6 \\
\hline Abril & 179,2 & 71 & 21,1 & 53,5 & 60 & 24,7 & 32,6 & 55 & 22,0 & 164,0 & 58 & 22,3 & 112,9 & 55 & 21,7 & 64,8 & 56 & 22,2 \\
\hline Maio & 129,1 & 73 & 18,9 & 4,7 & 60 & 21,9 & 5 , & 50 & 19,8 & 0 & 49 & 20,3 & 31,9 & 58 & 20,7 & 2,5 & 50 & 20,3 \\
\hline Junho & 14,3 & 60 & 18,1 & 22,6 & 55 & 20,4 & 1,5 & 44 & 19,3 & 0 & 43 & 18,5 & 0 & 49 & 19,0 & 0 & 48 & 18,7 \\
\hline Ten & 368,7 & & & 1457,9 & & & 1020,9 & & & 08 & & & 98 & & & 1279,4 & & \\
\hline
\end{tabular}
1996/97 a 2001/02 
Tabela 2. Vazão média mensal e anual $\mathrm{em} \mathrm{m}^{3} \mathrm{~s}^{-1}$ no Córrego Capetinga, nos anos hidrológicos de 1996/97 a 2001/02

\begin{tabular}{lcccccc}
\hline \multicolumn{1}{c}{ Meses } & $1996 / 97$ & $1997 / 98$ & $1998 / 99$ & $1999 / 00$ & $2000 / 01$ & $2001 / 02$ \\
\hline Julho & 0,064 & 0,086 & 0,056 & 0,035 & 0,055 & 0,074 \\
Agosto & 0,061 & 0,066 & 0,040 & 0,028 & 0,044 & 0,049 \\
Setembro & 0,052 & 0,060 & 0,032 & 0,029 & 0,063 & 0,043 \\
Outubro & 0,061 & 0,041 & 0,033 & 0,040 & 0,042 & 0,099 \\
Novembro & 0,091 & 0,092 & 0,282 & 0,210 & 0,216 & 0,151 \\
Dezembro & 0,182 & 0,143 & 0,206 & 0,301 & 0,377 & 0,184 \\
Janeiro & 0,332 & 0,273 & 0,130 & 0,601 & 0,300 & 0,293 \\
Fevereiro & 0,264 & 0,410 & 0,085 & 0,388 & 0,232 & 0,321 \\
Março & 0,438 & 0,371 & 0,199 & 0,329 & 0,426 & 0,366 \\
Abril & 0,222 & 0,241 & 0,099 & 0,228 & 0,300 & 0,240 \\
Maio & 0,134 & 0,146 & 0,064 & 0,133 & 0,155 & 0,115 \\
Junho & 0,106 & 0,098 & 0,048 & 0.085 & 0,099 & 0,069 \\
Média & 0,167 & 0,169 & 0,106 & 0,201 & 0,192 & 0,167 \\
\hline
\end{tabular}

Tabela 3: Média dos intervalos de vazão (Q) em $\mathrm{Ls}^{-1}$ e respectivas freqüências acumuladas $(\mathrm{Fa}) \mathrm{em} \%$

\begin{tabular}{cccccccc}
\hline $\mathrm{Q}$ & $\% \mathrm{Fa}$ & $\mathrm{Q}$ & $\% \mathrm{Fa}$ & $\mathrm{Q}$ & $\% \mathrm{Fa}$ & $\mathrm{Q}$ & $\% \mathrm{Fa}$ \\
\hline 583,0 & 1,38 & 279,5 & 23,61 & 118,5 & 51,39 & 56,5 & 80,55 \\
548,5 & 1,38 & 248,0 & 29,16 & 115,5 & 51,39 & 53,5 & 81,94 \\
516,0 & 1,38 & 218,5 & 33,33 & 105,0 & 52,78 & 50,5 & 83,33 \\
485,0 & 1,38 & 205,5 & 37,50 & 98,5 & 58,33 & 47,5 & 84,72 \\
456,0 & 1,38 & 193,0 & 37,50 & 92,5 & 61,11 & 44,5 & 87,50 \\
429,0 & 4,17 & 181,5 & 40,28 & 87,0 & 65,28 & 41,5 & 93,05 \\
403,5 & 5,55 & 171,0 & 40,28 & 81,5 & 65,28 & 39,0 & 93,05 \\
379,5 & 9,72 & 161,0 & 40,28 & 77,5 & 65,28 & 37,0 & 93,05 \\
357,0 & 12,50 & 151,5 & 43,05 & 72,5 & 66,67 & 35,0 & 94,44 \\
335,5 & 15,28 & 142,5 & 45,83 & 68,0 & 69,44 & 33,0 & 97,72 \\
315,5 & 16,67 & 134,0 & 50,00 & 64,0 & 73,61 & 31,0 & 97,72 \\
297,0 & 20,83 & 126,0 & 50,00 & 60,0 & 77,78 & 29,0 & 100,00 \\
\hline
\end{tabular}

$$
\alpha=0,78 \sigma_{\mathrm{x}-1}
$$

Enquanto a moda é dada por:

$$
\mu=\mathrm{x}_{\mathrm{m}}-0,577 \alpha
$$

em que:

$\mathrm{x}_{\mathrm{m}}$ - média dos eventos que compõem a série;

$\sigma_{\mathrm{x}-1}-$ desvio padrão da média.

Existem três condições para o valor de $\mathrm{k}$, a saber:

$1 . \mathrm{k}=0$, neste caso, diz-se que a distribuição é do tipo $1 \mathrm{ou}$ de Gumbel e pode ser aplicada para $-\infty<\mathrm{x}<\infty$;

$2 . \mathrm{k}<0$, caso em que se diz que a distribuição é do tipo 2 ou de Frechet e pode ser aplicada na condição de $(\mu+\alpha / \kappa)) \leq x<\infty$;

3. $\mathrm{k}>0$, diz-se que a distribuição é do tipo 3 ou de Weibull e pode ser aplicada para $-\infty<\mathrm{x} \leq(\mu+\alpha / \kappa)$; nos três casos, $\alpha$ tem que ser positivo.

Tanto na previsão de eventos mínimos quanto na previsão de eventos extremos, a distribuição do tipo 1 ou de Gumbel pode ser aplicada (Chow et al., 1988; Waylen \& Caviedes, 1990). Para $\mathrm{k}=0$ a Eq. (2) toma a seguinte forma:

$$
F(x)=\exp \left[-\exp \left(-\frac{x-\mu}{\alpha}\right)\right]
$$

Introduzindo-se o conceito de variável reduzida da distribuição (b) o qual é dado por:

$$
\mathrm{b}=(\mathrm{x}-\mu) / \alpha
$$

na Eq. (5) a mesma se transforma em:

$$
F(x)=\exp [-\exp (-b)]
$$

A Eq. (7) pode ser usada para se calcular a probabilidade $\mathrm{P}(\mathrm{x})$ de não ocorrer, no futuro, um evento de magnitude igual $\mathrm{x}$, enquanto a probabilidade $\mathrm{P}^{\mathrm{c}}(\mathrm{x})$ de que no futuro ocorra um evento maior ou igual a $\mathrm{x}$, é dada pelo complemento de $\mathrm{P}(\mathrm{x})$, ou seja, $\mathrm{P}^{\mathfrak{c}}(\mathrm{x})=1-\mathrm{P}(\mathrm{x})$. Substituindo-se essas duas últimas relações na Eq. (7), tem-se:

$$
\mathrm{P}(\mathrm{x})=\exp [-\exp (-\mathrm{b})]
$$

e

$$
\mathrm{P}^{\mathrm{c}}(\mathrm{x})=1-\exp [-\exp (-\mathrm{b})]
$$

A Eq. (4), de acordo com Gumbel citado por Cruciani (1980), somente pode ser aplicada a séries longas normalmente não disponíveis na engenharia; portanto, Gumbel sugeriu as seguintes equações corrigidas para se obter maior precisão nos cálculos da moda e da variável reduzida.

$$
\mu=x_{m}-\sigma_{x-1} \frac{y_{n}}{\sigma_{n}}
$$

e

$$
\alpha=\sigma_{\mathrm{n}} / \sigma_{\mathrm{x}-1}
$$

com essas modificações, a variável reduzida b passa a ser descrita pela equação:

$$
\mathrm{b}=\frac{\sigma_{\mathrm{n}}}{\sigma_{\mathrm{x}-1}}\left(\mathrm{x}-\mathrm{x}_{\mathrm{m}}+\sigma_{\mathrm{x}-1} \frac{\mathrm{y}_{\mathrm{n}}}{\sigma_{\mathrm{n}}}\right)
$$


em que:

$\sigma_{\mathrm{n}}$ - desvio-padrão reduzido

$\mathrm{y}_{\mathrm{n}}$ - média reduzida

tanto os valores de $y_{n}$ quanto os de $\sigma_{n}$ são tabelados em função do comprimento da série. Isolando-se a variável x na Eq. (12), tem-se:

$$
\mathrm{x}=\mathrm{x}_{\mathrm{m}}+\frac{\sigma_{\mathrm{x}-1}}{\sigma_{\mathrm{n}}}\left(\mathrm{b}-\mathrm{y}_{\mathrm{n}}\right)
$$

Visto que x é o evento procurado a determinado nível de probabilidade. Define-se período de retorno de um evento, $\mathrm{T}(\mathrm{x})$ como o inverso da probabilidade $\mathrm{P}(\mathrm{x})$ de ocorrência desse evento.

No caso da análise de máximos procura-se a menor probabilidade de que o evento procurado x ocorra, isto é, $\mathrm{P}^{\prime}(\mathrm{x})$; no caso da análise de mínimos, procura-se pela maior probabilidade de que o evento desejado ocorra em intensidade maior ou igual a $\mathrm{x}$, ou seja, procura-se pelo complemento de $\mathrm{P}^{‘}(\mathrm{x})$; por esta razão, na análise dos eventos mínimos utilizouse, para calcular o valor da variável reduzida b, a Eq. (8) e a Eq. (9) na análise dos eventos máximos. Depois de se calcular os valores de b, os mesmos foram substituídos na Eq. (13) encontrando-se, assim, os valores dos eventos procurados para os períodos de retorno de 5, 10, 20, 50 e 100 anos.

\section{Construção das curvas de permanência}

A curva de permanência relaciona a vazão e a probabilidade de ocorrerem vazões maiores ou iguais ao valor da ordenada. No caso presente, as médias mensais da vazão estão apresentadas na Tabela 2; as quais foram divididas pela área da bacia para se encontrar as vazões específicas médias mensais. Para confecção das curvas de permanência procurouse estabelecer intervalos de classe de vazões de acordo com a magnitude desses eventos e, no caso presente, usou-se uma metodologia proposta por Tucci (1993) para estabelecer os intervalos de classe de vazão e as respectivas freqüências acumuladas.

\section{RESULTADOS E DISCUSSÃO}

\section{Precipitação e volume total de água escoado na bacia}

Comparando-se a Tabela 1 com a 2, verificou-se que as maiores médias anuais da vazão corresponderam, como se esperava, aos anos mais chuvosos, em que a média anual da vazão do ano mais seco foi de $0,106 \mathrm{~m}^{3} \mathrm{~s}^{-1} \mathrm{e}$ a do ano mais chuvoso, de $0,201 \mathrm{~m}^{3} \mathrm{~s}^{-1}$, enquanto a média geral da bacia foi, nesses 6 anos estudados, de $0,167 \mathrm{~m}^{3} \mathrm{~s}^{-1}$; ainda de acordo com a Tabela 2 verificou-se que as médias mensais de vazão variaram de um mínimo de $0,028 \mathrm{~m}^{3} \mathrm{~s}^{-1}$ a um máximo de $0,601 \mathrm{~m}^{3} \mathrm{~s}^{-1}$, ambas, no ano hidrológico 1999/2000.

Integrando as vazões médias mensais e acumulando-as mês a mês, obteve-se o volume total escoado na bacia, cujo correspondente em lâmina foi de $3.295,8 \mathrm{~mm}$, ao passo que o total precipitado foi de $8.223,6 \mathrm{~mm}$. Dividindo-se o total escoado pelo total precipitado, encontrou-se o módulo médio de escoamento da bacia que foi, nesses seis anos, igual a 0,40.

Verificou-se que as médias mínimas mensais ocorreram nos meses de agosto, setembro e outubro, com variação de $87 \%$ entre o maior e o menor valor médio mínimo (Tabela 2); no entanto, as mínimas com duração de sete dias nem sempre coincidiram com os meses de menores disponibilidades hídricas; justifica-se tal fato em virtude das mínimas com duração de sete dias terem coincidido com o fim do período seco.

Associando os totais anuais de precipitação às vazões médias anuais, encontrou-se uma função potencial que descreve a vazão média anual $(\mathrm{Qm})$, por meio de:

$$
\mathrm{Qm}=7,47 \times 10^{-6} \mathrm{P}^{1,386}
$$

em que:

P - precipitação média anual

O coeficiente de determinação $\left(R^{2}=0,933\right)$ indica que a produção hídrica da bacia é função quase exclusiva do total precipitado.

\section{Curva de permanência e valores de $\mathbf{Q}_{95}$ e $\mathbf{q}_{95}$}

$\mathrm{Na}$ Tabela 3 mostra-se as médias dos intervalos das classes de vazão e a freqüência acumulada das respectivas médias. De forma seme-lhante são apresentados, na Tabela 4, os mesmos parâmetros para a vazão específica. Com esses dados confeccionaram-se as curvas de permanência para a vazão total e vazão específica, conforme pode ser visualizado nas Figuras 2 e 3, respectivamente.

Tabela 4. Média dos intervalos de vazão específica, (q) em $\mathrm{Ls}^{-1} \mathrm{~km}^{-2}$ e respectivas freqüências acumuladas $(\mathrm{Fa}) \mathrm{em} \%$

\begin{tabular}{cccccccc}
\hline $\mathrm{q}$ & $\mathrm{Fa}$ & $\mathrm{q}$ & $\mathrm{Fa}$ & $\mathrm{q}$ & $\mathrm{Fa}$ & $\mathrm{Q}$ & $\mathrm{Fa}$ \\
\hline 60,6 & 1,38 & 29,0 & 23,61 & 12,3 & 51,39 & 5,9 & 80,55 \\
57,0 & 1,38 & 25,8 & 29,16 & 12,0 & 51,39 & 5,6 & 81,94 \\
53,6 & 1,38 & 22,7 & 33,33 & 10,9 & 52,78 & 5,2 & 83,33 \\
50,4 & 1,38 & 21,4 & 37,50 & 10,2 & 58,33 & 4,9 & 84,72 \\
47,4 & 1,38 & 20,1 & 37,50 & 9,6 & 61,11 & 4,6 & 87,50 \\
44,6 & 4,17 & 19,9 & 40,28 & 9,0 & 65,28 & 4,3 & 93,05 \\
41,9 & 5,55 & 17,8 & 40,28 & 8,5 & 65,28 & 4,1 & 93,05 \\
39,4 & 9,72 & 16,7 & 40,28 & 8,1 & 65,28 & 3,8 & 93,05 \\
37,1 & 12,50 & 15,7 & 43,05 & 7,5 & 66,67 & 3,6 & 94,44 \\
34,9 & 15,28 & 14,8 & 45,83 & 7,1 & 69,44 & 3,4 & 97,72 \\
32,8 & 16,67 & 13,9 & 50,00 & 6,7 & 73,61 & 3,2 & 97,72 \\
30,9 & 20,83 & 13,1 & 50,00 & 6,2 & 77,78 & 3,0 & 100,00 \\
\hline
\end{tabular}

De acordo com essas curvas, encontraram-se os valores de $34,5 \mathrm{~L} \mathrm{~s}^{-1} \mathrm{e} 3,5 \mathrm{~L} \mathrm{~s}^{-1} \mathrm{~km}^{-2}$ para $\mathrm{Q}_{95} \mathrm{eq}_{95}$, respectivamente, significando que em 95\% do tempo espera-se encontrar uma vazão maior ou igual aos valores anteriormente mencionados. Verifica-se de imediato que a divisão da $\mathrm{Q}_{95}$ pela área da bacia não corresponde aproximadamente ao valor da $\mathrm{q}_{95}$, mostrando desta forma que para obtenção da $\mathrm{q}_{95}$ não é necessário confeccionar mais uma curva de permanência, o que na realidade é uma simplificação desejável. 


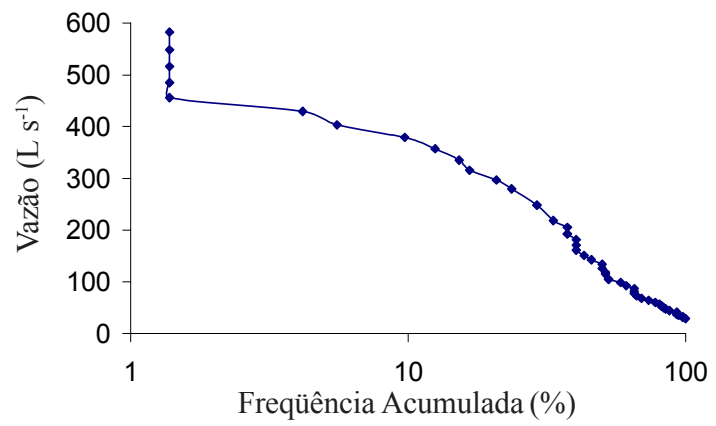

Figura 2. Curva de permanência das vazões médias mensais do córrego Capetinga

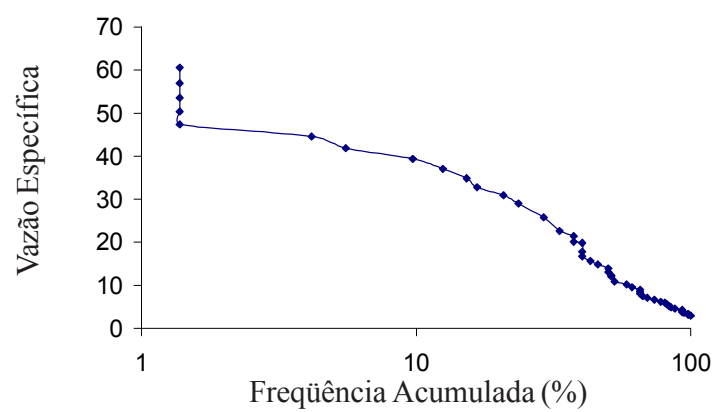

Figura 3. Curva de permanência das vazões específicas médias mensais do córrego Capetinga

\section{Máximas vazões instantâneas}

$\mathrm{Na}$ Tabela $5 \mathrm{~A}$ estão apresentados os valores das maiores vazões instantâneas anuais (total e específica) do córrego Capetinga constituindo-se, portanto, em duas séries anuais de seis eventos cada uma maior que o mínimo, de cinco anos, aconselhável por Tucci (2001) para estudos de regionalização de vazões. Com os dados dessa tabela e por meio da Eq. (9) determinou-se o valor da variável reduzida b para períodos de retorno de 5, 10, 20, 50 e 100 anos. Após se calcular a média e o desvio padrão da referida série e a obtenção de $y_{n}$ e $\sigma_{n}$ em tabelas apropriadas, foram encontrados, conforme a Eq. (13), os valores de vazão para os referidos períodos de retorno, conforme o exposto na Tabela 6. Teoricamente, a média da série na distribuição de Gumbel corresponde, segundo Chow et al. (1988) a um período de retorno igual a 2,33 anos. Tomando-se este ponto e o evento simulado para um período de retorno de 100 anos e levando-os ao papel de probabilidade de Gumbel, possibilita-se o traçado de uma reta, conforme pode ser visualizado na Figura 4, denominada reta de probabilidade teórica. Plotando-se nesta figura os valores das máximas cheias observadas (dadas na Tabela 5A), os respectivos períodos de retorno e os eventos simulados para os períodos de retorno de 5, 10, 20 e 50 anos (dados na Tabela 6), percebe-se, de imediato, a proximidade ou a coincidência dos referidos pontos, signifi-cando um ajuste muito bom dado pela distribuição de Gumbel no caso das máximas vazões anuais.

\section{Mínimas vazões com duração de sete dias}

$\mathrm{Na}$ Tabela 5B encontram-se as menores vazões anuais com duração de sete dias (total e específica) do córrego Capetinga. Essas vazões não foram obtidas mediante a cota registrada no linígrafo e, sim, por meio da medição semanal da vazão, usandose um micro molinete para atingir esse objetivo; tal providência foi tomada em virtude dos baixos valores das vazões encontradas no córrego nos períodos mais secos do ano, os quais poderiam não ser confiáveis se determinados a partir das cotas registradas do nível de água. Com o uso da Eq. (8) para

Tabela 6. Vazões máximas instantâneas (Qmáx) e vazões específicas máximas instantâneas (qmáx) $\mathrm{em} \mathrm{m}^{3} \mathrm{~s}^{-1}$, vazões mínimas com duração de sete dias (Qmín) e vazões específicas mínimas (qmín) em $\mathrm{L} \mathrm{s}^{-1}$ com duração de sete dias, no Córrego Capetinga para diversos períodos de retorno (T) em anos

\begin{tabular}{rcccc}
\multicolumn{1}{c}{$\mathrm{T}$} & $\begin{array}{c}\text { Qmáx } \\
\left(\mathrm{m}^{3} \mathrm{~s}^{-1}\right)\end{array}$ & $\begin{array}{c}\text { Qmáx } \\
\left(\mathrm{m}^{3} \mathrm{~s}^{-1} \mathrm{~km}^{-2}\right)\end{array}$ & $\begin{array}{c}\text { Qmín } \\
\left(\mathrm{L} \mathrm{s}^{-1}\right)\end{array}$ & $\begin{array}{c}\text { Qmín } \\
\left(\mathrm{L} \mathrm{s}^{-1} \mathrm{~km}^{-2}\right)\end{array}$ \\
\hline 5 & 13,648 & 1,415 & 24,71 & 2,56 \\
10 & 17,217 & 1,786 & 20,86 & 2,16 \\
20 & 20,644 & 2,141 & 18,03 & 1,87 \\
50 & 25,079 & 2,601 & 15,06 & 1,57 \\
100 & 28,400 & 2,945 & 13,41 & 1,39 \\
\hline
\end{tabular}

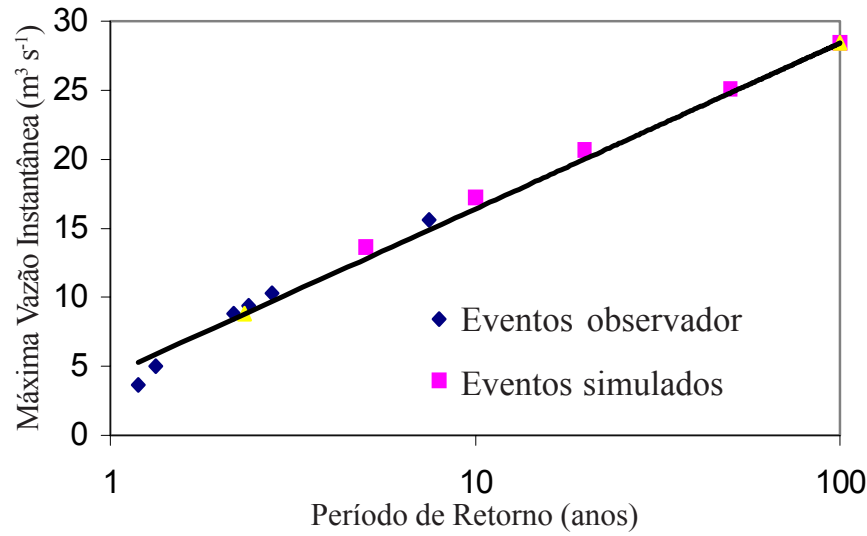

Figura 4. Distribuição dos eventos máximos instantâneos observados e simulados, conforme o período de retorno

Tabela 5. Vazões máximas instantâneas (Qmax), vazões instantâneas máximas específicas (qmax), vazões mínimas com duração de sete dias (Qmin) e vazões mínimas específicas com duração de sete dias (qmin) ocorridas no córrego Capetinga

\begin{tabular}{|c|c|c|c|c|c|c|}
\hline Ano Hidrológico & $1996 / 97$ & $1997 / 98$ & $1998 / 99$ & $1999 / 00$ & $2000 / 01$ & $2001 / 02$ \\
\hline Ocorrência & $12 / 12 / 96$ & $8 / 2 / 98$ & $04 / 12 / 98$ & $18 / 1 / 00$ & $5 / 3 / 01$ & $21 / 3 / 02$ \\
\hline \multicolumn{7}{|c|}{ A. Vazão máxima instantânea } \\
\hline Qmáx $\left(\mathrm{m}^{3} \mathrm{~s}^{-1}\right)$ & 8,815 & 4,984 & 3,683 & 15,606 & 10,294 & 9,390 \\
\hline Ocorrência & 9 a $16 / 10 / 96$ & 1 a $7 / 11 / 97$ & 1 a $7 / 10 / 98$ & 24 a $31 / 8 / 99$ & 1 a $7 / 10 / 00$ & 23 a $30 / 9 / 01$ \\
\hline \multicolumn{7}{|l|}{ B. Vazão mínima } \\
\hline
\end{tabular}


calcular o valor da variável reduzida b e o restante da metodologia usada idêntica ao item anterior, determinaram-se os valores das mínimas vazões anuais com duração de sete dias para os respectivos períodos de retorno, conforme a Tabela 6. Também, para essas vazões e de forma semelhante ao caso anterior, confeccionou-se a Figura 5, na qual se percebe pequena discrepância entre a reta e os eventos mínimos observados no córrego em estudo (Tabela 5B) e entre os eventos simulados (Tabela 6).

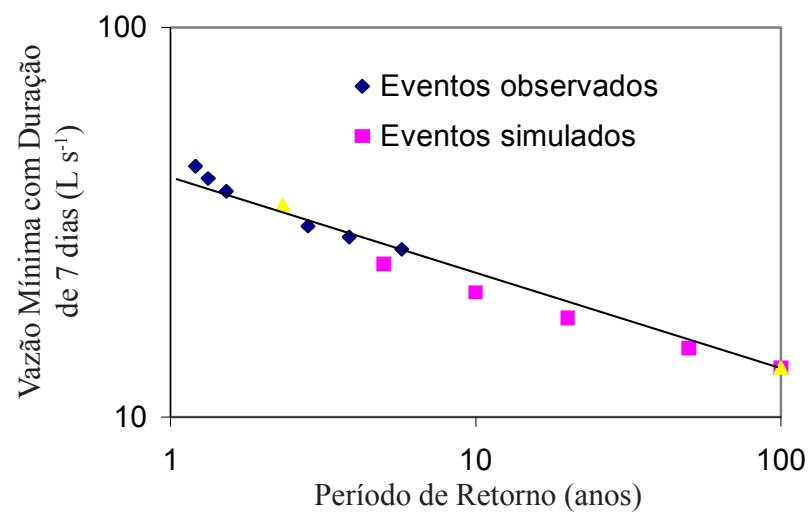

Figura 5. Distribuição dos eventos mínimos observados e simulados, conforme o período de retorno

\section{CONCLUSÕES}

1. Na maioria das vezes, março foi o mês dentro da série analisada de maior disponibilidade hídrica.

2. A mínimas médias mensais ocorreram nos meses de agosto, setembro e outubro, com variação de $87 \%$ entre a maior e a menor média mínima.

3. A vazão especifica associada à permanência de $95 \%\left(\mathrm{q}_{95}\right)$, pode ser determinada pela divisão da vazão associada à mesma permanência $\left(Q_{95}\right)$ pela área da bacia, sendo portanto desnecessário a confecção de duas curvas.

4. A distribuição de Gumbel se encaixou muito bem na previsão das máximas vazões anuais, mostrando um ajuste muito bom entre a reta de probabilidade teórica e os eventos observados e simulados.

5. No caso das mínimas vazões anuais com duração de sete dias, a distribuição de Gumbel apresentou uma ligeira discrepância entre a reta de probabilidade teórica e os eventos observados e simulados.

\section{AGRADECIMENTOS}

O autor agradece: Ao técnico em hidrologia da Faculdade de Agronomia e Medicina Veterinária da Universidade de Brasília, Sr. Manuel Pereira de Oliveira Júnior, pelo cuidado e dedicação exigidos na coleta dos eventos meteorológicos e hidrológicos. Ao pesquisador da EMBRAPA Cerrados, Jorge Enoc Furquim Wernec, pela cessão da Figura 1, e aos professores doutores Eiyti Kato e Carlos Alberto da Silva Oliveira, pelas sugestões apresentadas.

\section{LITERATURA CITADA}

Bur, D.H. Catchment similarity for regional flood frequency analysis using seasonality measures. Journal of Hydrology, Amsterdam, v.202, p.212-230,1997.

Chow, V.T.; Maidment, D.R.; Mays, L.W. Applied hydrology. 1. ed. New York: Mc Graw-Hill publishing Company, 1988. $572 p$.

Christofidis D. Os recursos hídricos e a prática da irrigação no mundo. Irrigação e Tecnologia Moderna, Brasília, n.49, p.813, 2001.

Cruciani, D.E. A drenagem na agricultura. 1. ed. São Paulo: Livraria Nobel S.A., 1980. 333p.

Haktanir, T. Comparison of various flood frequency distributions using annual flood peaks data of rivers in Anatolia. Journal of Hydrology, Amsterdam, v.136, p.1-31,1992.

Lima, J.E.F.W. Determinação da evapotranspiração de uma bacia hidrográfica sob vegetação natural de cerrado, pelo método do balanço hídrico.Brasília: UnB, 2000. 53p. Dissertação Mestrado

Pires, C.L.F. Análise de freqüência - revisão metodológica. Ciência e Tecnologia, Rio de Janeiro, v.2, p.13-22. 1996.

Silveira, G.S.; Cruz, J.C.; Irion, C.A.; Oliveira M.G.; Tucci, C.E.; Clarke, R.T.; Cruz, Souza, M.A. Informações hidrológicas em pequenas bacias hidrográficas rurais. Ciência e Tecnologia, Rio de Janeiro, v.4, p.18-27. 1994

Tawn, J.A. An extreme value theory model for dependent observation. Journal of Hydrology, Amsterdam, v.101, p.227250. 1988.

Tucci, C.E. Hidrologia - ciência e aplicação. 2. ed. Porto Alegre: Editora da Universidade Federal do Rio Grande do Sul, 2001. 943p.

Waylen, P.R.; Caviedes, C.N. Annual and seasonal fluctuations of precipitation and streamflow in the Aconcagua river basin, Chile. Journal of Hydrology, Amsterdam, v.102, p.79-88. 1990. 